\title{
13q12.3 microdeletion syndrome
}

INSERM

\section{Source}

INSERM. (1999). Orphanet: an online rare disease and orphan drug data base. 13912.3 microdeletion syndrome. ORPHA:412035

$13 q 12.3$ microdeletion syndrome is a rare chromosomal anomaly characterized by moderate intellectual disability, speech delay, postnatal microcephaly, eczema or atopic dermatitis, characteristic facial features (malar flattening, prominent nose, underdeveloped alae nasi, smooth philtrum, and thin vermillion of the upper lip), and reduced sensitivity to pain. 